\title{
Effect of Seismic Pounding between Reinforced Concrete Buildings
}

\author{
Arpitha K \\ P.G Student, Department of Civil Engineering, \\ A C S. College of Engineering, Karnataka, India \\ Umadevi R \\ Assistant Professor, Department of Civil Engineering, \\ A C S. College of Engineering, Karnataka, India
}

\begin{abstract}
During earthquakes the buildings which are closely spaced structures with insufficient gap between them have a chance of pounding on the adjacent building block. The present day scenario in urban areas buildings were built very close to each other for the complete usage of limited space. So in this study an attempt was made to analyse the seismic response due to pounding between the $\mathrm{RC}$ buildings that are built without sufficient separation gap. A model of two buildings close to each other one being G+4 storey and other being G+7 storey were considered. The parameters like displacement and impact force were considered for the dynamic analysis using ETABS 2015 software. The design approach used in this study, ensure that structures possess a minimum strength to withstand minor and modern earthquakes without being structurally damaged. The objective of this study is to withstand a major earthquake without collapse by considering past ground acceleration for RC buildings.
\end{abstract}

Keywords - Nonlinear Analysis, Pounding, Reinforced Concrete Buildings, Adjacent Structures.

\section{INTRODUCTION}

Seismic waves have cause a reason for incredible obliteration for humanity. Investigation of history shows extreme damages of built engineering structures like bridges, commercial enterprises and air terminal cause's incredible monetary misfortunes to the nation. Structures with their foundations laying on unconsolidated landfill are at risk since they can be shaken off their foundations during an earthquake. At this point when a quake happens in a populated zone, it might bring about deaths and injuries on a substantial scale and extensive damage of property is caused. The expansion in population in urban areas causes to rise costs of housing and land is a great classic example for more constructions. This prompts the development of elevated structures with less separation gap between each other, yet during earthquake these structures pound with each other.

During earthquake, nearby structures will pound with each other because of their diverse dynamic characteristics, out of phase development and because of insufficient separation gap between adjoining structures is known as seismic pounding. Structures like residential building, industrial structures and commercial complexes are normally built near each other in urban zones and metropolitan areas as well, where the area cost is high further more because of conservative perspective greatest area utilization necessities. Because of the close proximity of these structures, they have regularly been found to affect each other while reacting to seismic induced waves and strong ground motion. An earthquake can bring about sudden development of the ground that is transferred to the structure through ground to foundation. Because of its enormous mass the structures will vibrate with extensive force and large momentum cause more damages during pounding. Accordingly, it has been recognized that pounding is a unpredictable marvel phenomenon that ought to be averted or moderated with appropriate design.

The best and most effective technique to reduce pounding damage is to give adequate separation gap. Sometimes it turns out to be difficult to implement in sites, since expense of area is high and specifying detailing issues. A substitute to the procurement of separation gap in the outline of building helps to reduce the impact of damage by pounding by reducing sidelong sway movement of the structure which can be accomplished by providing lateral load resisting system and, along these lines parallel dislodging of the structures can be in- phase with each other.

Seismic pounding between adjacent buildings usually occur when the structures are in the following patterns, 1. adjacent buildings with same heights and same floor levels.

2. Adjacent buildings with same floor levels but different heights. 
3. adjacent buildings with different total height and different floor levels.

4. Buildings situated in a row.

5. adjacent buildings with different dynamic characteristics.

6. adjacent buildings with unequal heights, pounding may occur in columns.

7. adjacent buildings with unequal distribution of mass and stiffness.

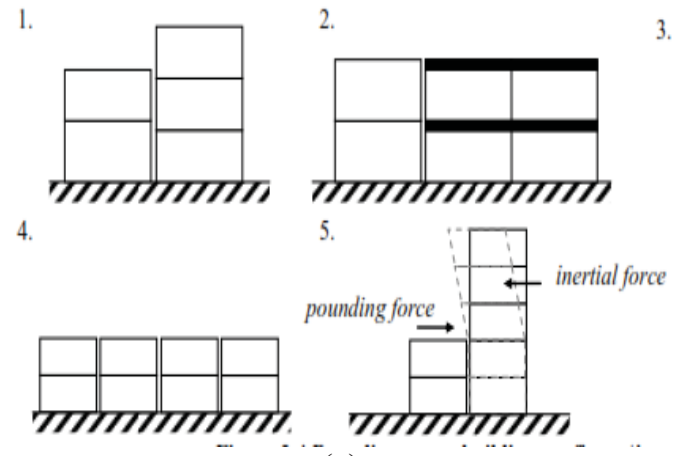

(a)
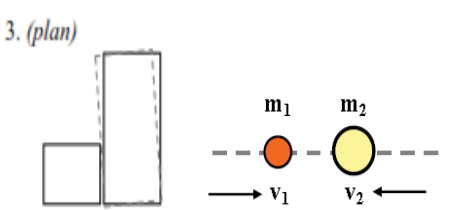

APPROACH

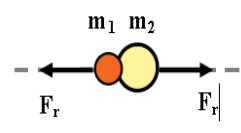

RESTITUTION

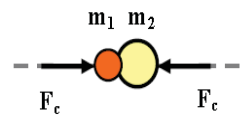

COMPRESSION

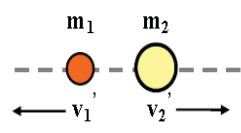

SEPARATION

(b)

Figure 1: Representation of different places where pounding may occur and its Stages of impact

\section{OBJECTIVE OF THE STUDY}

The objective of the present study is to evaluate the effects Seismic Pounding between Reinforced Concrete Buildings by non linear (time history) analysis and linear responce spectrum analysis using three dimensional finite element analysis software ETAB's. The primary aim of this study is to analyse the effect of pounding between R.C buildings with different and same floor height and set back.

\section{III.REVIEW OF LITERATURE}

Pradeep Kumar, Ramancharla and ChennaRajaram (2012) They have done analysis of single storey structure with various setback and different storey heights by using FEA software SAP 2000. Gap element is provided between two adjacent structures to study the pounding impact force, models are analyzed using El-centro ground motion. Torsional pounding between the structures is studied for different setbacks with asymmetric and symmetric model. The pounding response changes altogether at various elevation levels than at Same elevation levels. The collision impact force at mid column to floor case, is more than compare to other height levels due to shear amplification induced due to earthquake. It was conclude that structures are at extreme levels of setback suffers more impact force than building without setback.

Reginald desroches, Susendarmuthukumar (2004) In this paper, they have studied a efficiency of various pounding models. They considered Kelvin, Hertz, contact force-based linear spring and stereo-mechanical models in order to study and record impact force due to seismic pounding of adjacent R.C structures. They have modeled adjacent structures for two degree of freedom system, which represents two buildings where just elastic system response is measured. As well as Hertz model with a nonlinear damper is also used for to studying seismic pounding. They considered parameter for two DOF system studies are type of impact model, ground motion records and characteristics, impact energy loss using reinstitution coefficient. The earthquake data of Whittier Narrows, Landers, Northridge, Loma Prieta, Morgan Hill, Imperial Valley, N Palm Springs and San Fernando are considered for the analysis.

Pradeep Kumar R, Kiran Kumar Reddy K, Chandra Sekhara Reddy T (2014) In this study gap link elements were connected at each floors to floor node between adjacent buildings to know the impact force due to pounding. The FEMA method of analysis was done for buildings for different cases, like buildings of different same and different floor level. It was found that the impact force due to pounding was more in buildings with different floor levels when compared with the buildings at same floor levels and exterior buildings suffered more damage than interior buildings. While considering adjacent R.C buildings with different dynamic properties with and same dynamic properties vibrate out of its regular phase and suffer pounding. 


\section{METHODOLOGY AND ANALYSIS}

The techniques currently in used for this study are Dynamic analysis by considering both Non-Linear Dynamic and Linear Dynamic analysis.

A. Time history analysis-This technique is known to be most sophisticated and accurate technique for dynamic analysis of RC buildings. In this technique the sophisticated mathematical model of previous earthquake data were used to analyse structure, which may subjected to future seismic activities. In this study time History analysis are performed by considering the El centro earthquake data which also known as the Imperial Valley Earthquake recorded from May 18, 1940 as shown in figure 2. The Elcentro earthquake recorded data has 5000 data points with a sampling period of 0.02 seconds with peak ground acceleration of $0.226 \mathrm{~g}$.

B. Response Spectrum Analysis- This method gives the result with speed and accuracy. The in-plane phase of vibration are calculated by time period and mode shape for the maximum response value corresponding to each modes with reference to a response spectrum curve. There are disadvantages of using this approach where this technique calculate a huge amount of information, which require an enormous amount of computational work and time to conduct all possible design checks. This technique must be repeated for many different earthquake ground motions, to check that all the modes are excited. The response spectrum for one ground motions, in a specified direction repersent a smooth curve function. This analysis performed for the zone V, and for soft soil sites as per IS 1893 (Part-1) 2002 for the six different cases. The spectral acceleration coefficient values for the natural time periods of 0 to 4 seconds are calculated as stated in the above equations as shown in the figure 3 .

The selected model of two buildings consist of eight storey and five storey where the dimension of both the buildings is 15 X $15 \mathrm{~m}$ with floor height of $3.2 \mathrm{~m}$ and $3 \mathrm{~m}$. The slab with Rigid floor diaphragm thickness is $0.15 \mathrm{~m}$ and all column are of $0.30 \times 0.40 \mathrm{~m}$. The models are computed for an expansion joint of $80 \mathrm{~mm}$. These models were analyzed using ETABS 2015. Live load applied on floor and roof is taken as $3 \mathrm{kN} / \mathrm{m}^{2}$ and $1.5 \mathrm{kN} / \mathrm{m}^{2}$. The floor finish applied as load on each floor of $1.2 \mathrm{KN} / \mathrm{m}^{2}$, Wall load of $12.32 \mathrm{kN} / \mathrm{m}$ and parapet wall load of $4.95 \mathrm{kN} / \mathrm{m}$ is applied on the beams. The building is ordinary moment resisting frame is analyzed, intended for commercial use.

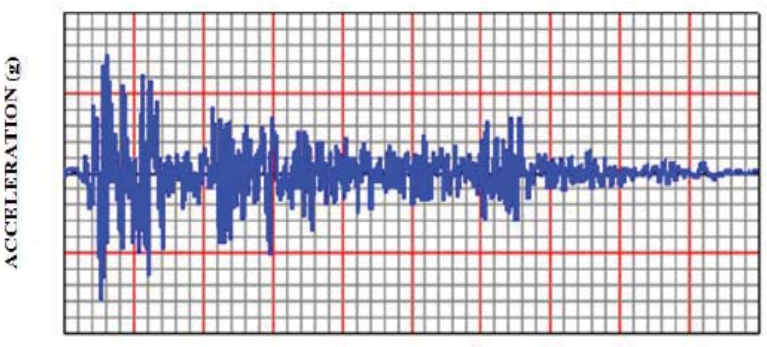

$\operatorname{TINE}(\mathrm{sec})$

Figure 2:Shows Acceleration Vs Time graph of El centro earthquake, 1940

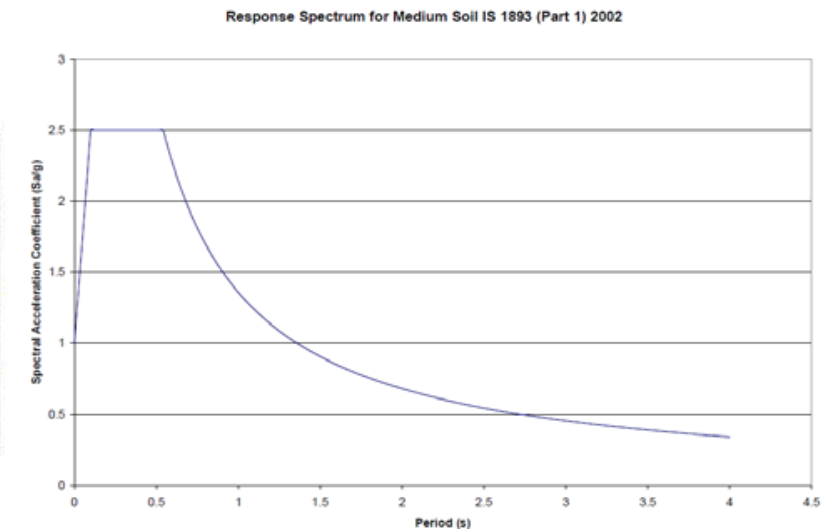

Figure 3: Shows the Response Spectrum Function (Sa/g) Vs. Period

\section{NON-LINEAR STIFFNESS ELEMENT (GAP ELEMENT)}

In order to known the impact force due to pounding in the adjacent buildings under seismic excitation, a gap element as a link is provided to connect between the structures from node to node as shown in Figure 4, which shows the connection of gap elements between buildings. The expansion separation joint of structures is specified by gap element. The gap element is active when the gap becomes zero and usually gap elements are active in compression phase and becomes inactive in tension phase. The stiffness of the gap element is usually considered as $10^{2}$ to $10^{4}$ times the stiffness of the adjacent RC building or connected element. 


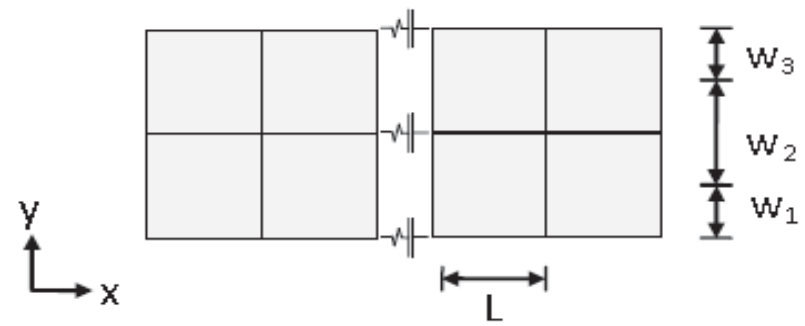

Figure 4: Shows the plan of two colliding floors showing axial element stiffness

Therefore non-linear stiffness element $(\mathrm{K})$ for this model is as follows;

$$
K=\frac{E A_{\underline{I}}}{L} \times 100
$$

$\mathrm{A}_{\mathrm{I}}=\mathrm{W}_{\mathrm{I}} \times \mathrm{t}$

$\mathrm{E}=$ Young's Modulus

$\mathrm{t}=$ Slab thickness

$\mathrm{W}_{\mathrm{I}}=$ Average element width

\section{RESULTS AND DISCUSSIONS}

The reinforced concrete building with floor height of $3.2 \mathrm{~m}$ and $3 \mathrm{~m}$ were analyzed. Let us considered six different RC building model such as,

Case 1- Adjacent buildings at equal floor level with different story height

Case 2- Adjacent buildings at equal floor level and story height

Case 3-Adjacent buildings at set back of $5 \mathrm{~m}$ with equal floor level and different story height

Case 4-Adjacent buildings at different story height and floor level

Case 5-Adjacent buildings at different floor level with same story height

Case 6-Adjacent buildings at setback of $5 \mathrm{~m}$ with different story height and different floor level
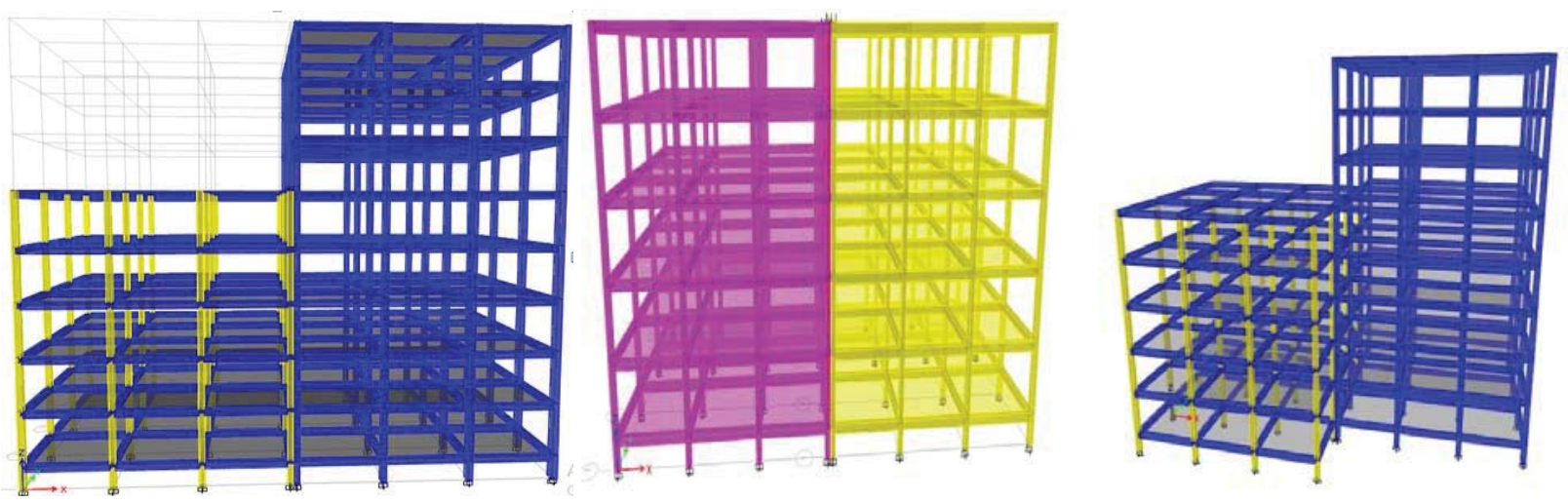

Figure 5: Shows RC buildings A and B with same floor levels with and without setback 


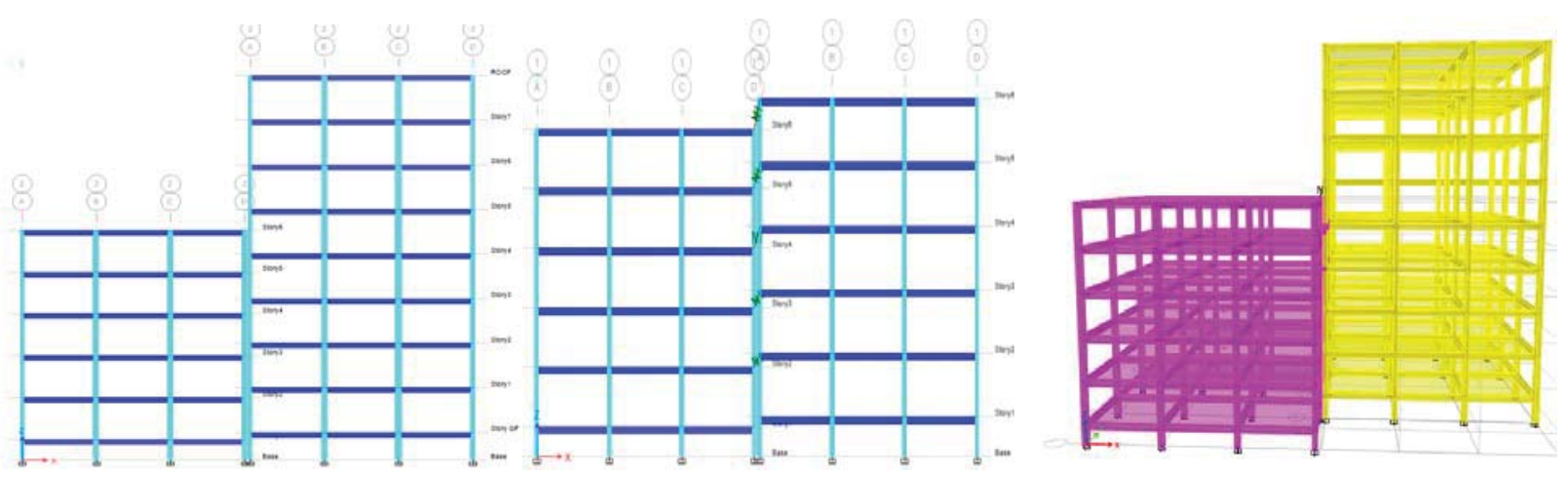

Figure 6: Shows RC buildings A and B at different floor levels with and without setback.

Time History Analysis- This analysis is carried out by considering non linear time history data of El-centro earthquake. For the above different six cases, graphs are presented for the models. The results of displacement, Acceleration, Impact force, Storey drift for above six cases at $\mathrm{G}+4$ storey level were discussed below.

\begin{tabular}{|c|c|c|c|c|c|c|c|}
\hline \multirow{2}{*}{ Case } & Models & \multicolumn{2}{|c|}{ Displacement $(\mathrm{mm})$} & \multicolumn{2}{c|}{ Acceleration $\left(\mathrm{m} / \mathrm{s}^{2}\right)$} & Impact force $(\mathrm{kN})$ \\
\cline { 3 - 8 } & $\mathrm{A}$ & $\mathrm{B}$ & $\begin{array}{c}\text { Total } \\
{[(\mathrm{A}+\mathrm{B})-80]}\end{array}$ & $\mathrm{A}$ & $\mathrm{B}$ & Gap element \\
\hline 1 & $\begin{array}{c}\text { Same floor to floor height } \\
\left(\mathrm{H}_{\mathrm{A}}=\mathrm{H}_{\mathrm{B}}\right)\end{array}$ & 158.04 & 248.71 & 326.75 & 10.59 & 5.98 & 743.44 \\
\hline 2 & $\begin{array}{c}\text { Same floor to floor level } \\
\left(\mathrm{H}_{\mathrm{A}}=\mathrm{H}_{\mathrm{B}}\right)\end{array}$ & 198.54 & 198.54 & 317.08 & 6.57 & 6.57 & 680.57 \\
\hline 3 & $\begin{array}{c}\text { Same floor to floor level with } \\
\text { Setback }\left(\mathrm{H}_{\mathrm{A}}=\mathrm{H}_{\mathrm{B}}\right)\end{array}$ & 153.076 & 255.37 & 328.446 & 6.696 & 4.801 & 704.42 \\
\hline 4 & $\begin{array}{c}\text { Different floor to floor height } \\
\left(\mathrm{H}_{\mathrm{A}} \neq \mathrm{H}_{\mathrm{B}}\right)\end{array}$ & 135.14 & 142.04 & 197.18 & 6.96 & 4.68 & 773.84 \\
\hline 5 & $\begin{array}{c}\text { Different floor to floor height } \\
\left(\mathrm{H}_{\mathrm{A}} \neq \mathrm{H}_{\mathrm{B}}\right)\end{array}$ & 138.487 & 194.916 & 253.405 & 7.07 & 6.86 & 720.69 \\
\hline 6 & $\begin{array}{c}\text { Different floor to floor height } \\
\text { with Setback }\left(\mathrm{H}_{\mathrm{A}} \neq \mathrm{H}_{\mathrm{B}}\right)\end{array}$ & 139.99 & 238.297 & 298.287 & 7.39 & 4.97 & 778.954 \\
\hline
\end{tabular}

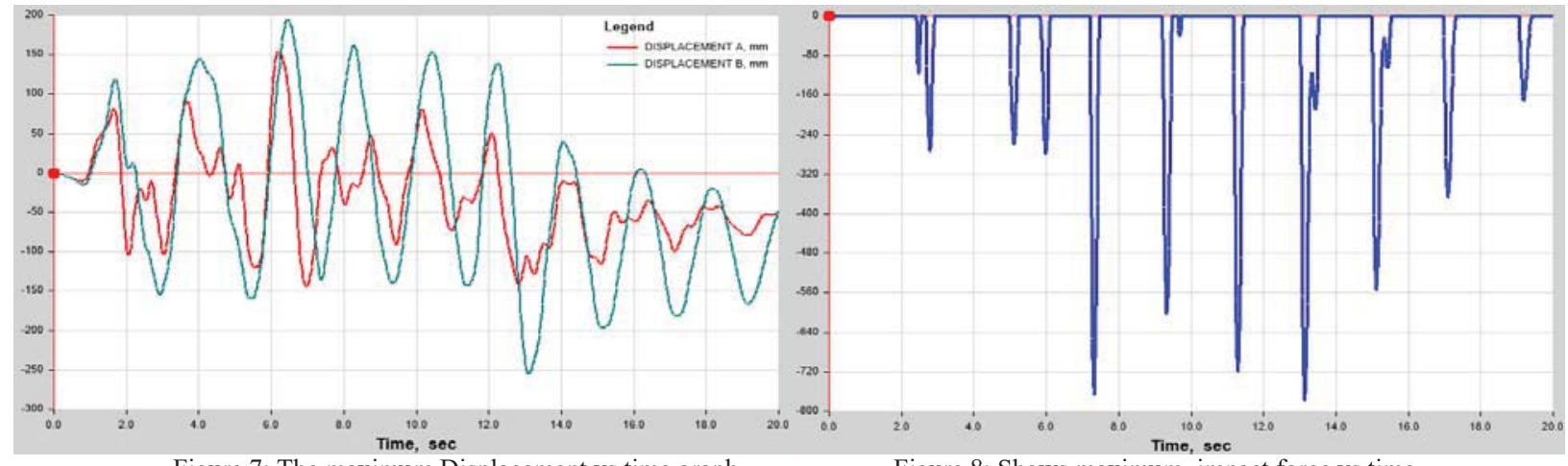

Figure 7: The maximum Displacement vs time graph at fifth floor for case 3 with set back.

Figure 8: Shows maximum impact force vs time graph at fifth floor for case 6 with setback. 


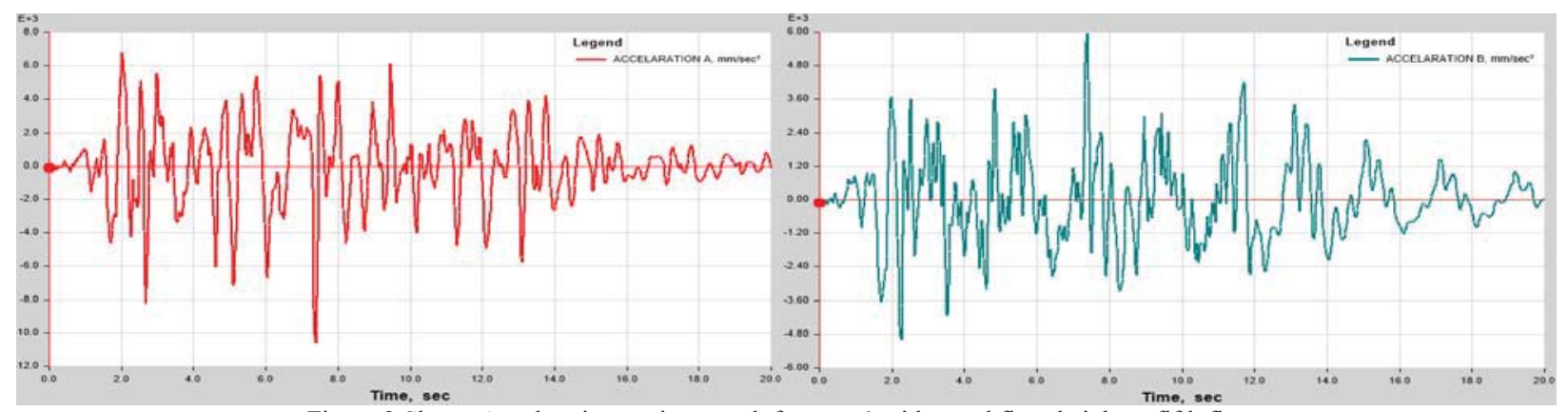

Figure 9:Shows Acceleration vs time graph for case 1 with equal floor height at fifth floor.
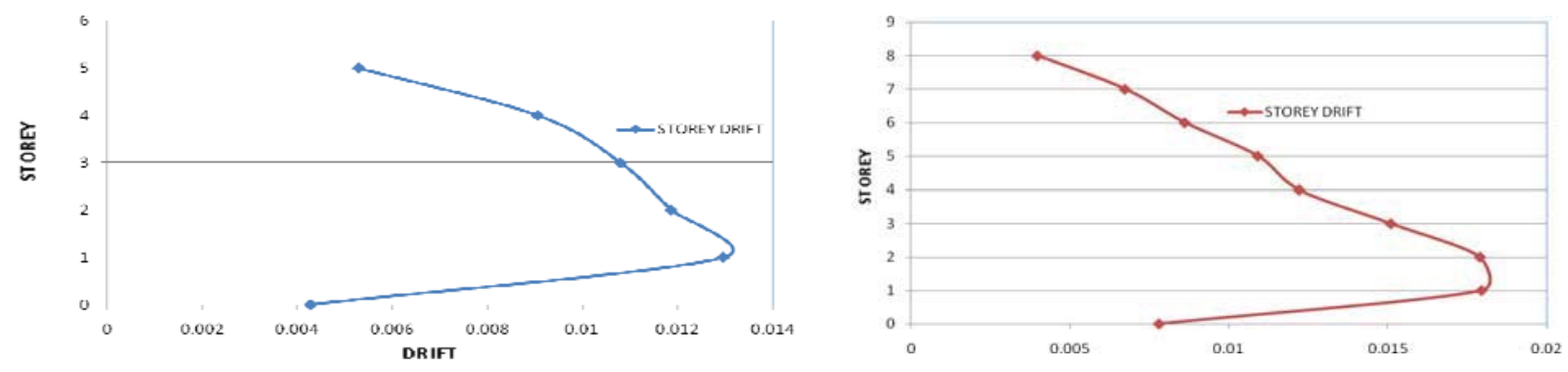

Figure 10: Shows a graph of Storey drift for 5 and 8 storey building

Non-linear dynamic analysis with El-centro ground motion data from past, used as a input to carried out the analysis, on those models to observe the behavior of the structure under severe ground motion in future.

Response Spectrum Analysis- This analysis technique have been practiced as prescribed data mentioned in IS codes 1893 ( part1) 2002. For above cases, graphs are presented for the models. The results for different cases is presented in terms of parameters such as displacement, acceleration, base shear, storey drift.

Table 2: Buildings without lateral load resisting systems subjected to pounding.

\begin{tabular}{|c|c|c|c|c|c|c|c|}
\hline \multirow{2}{*}{ Case } & Models & \multicolumn{3}{|c|}{ Displacement (mm) } & \multicolumn{2}{c|}{ Acceleration $\left(\mathbf{m} / \mathbf{s e c}^{2}\right)$} & \multirow{2}{*}{ Base shear (kN) } \\
\cline { 3 - 7 } & $\mathbf{A}$ & $\mathrm{B}$ & $\begin{array}{c}\text { Total } \\
{[(\mathrm{A}+\mathrm{B})-80]}\end{array}$ & $\mathrm{A}$ & $\mathrm{B}$ & \\
\hline $\mathbf{1}$ & $\begin{array}{c}\text { Same floor to floor height } \\
\text { for different story }\left(\mathrm{H}_{\mathrm{A}}=\mathrm{H}_{\mathrm{B}}\right)\end{array}$ & 44.21 & 70.99 & 35.2 & 0.714 & 0.404 & 2006.340 \\
\hline $\mathbf{2}$ & $\begin{array}{c}\text { Same story and floor level } \\
\left(\mathrm{H}_{\mathrm{A}}=\mathrm{H}_{\mathrm{B}}\right)\end{array}$ & 50.00 & 50.00 & 20.0 & 0.771 & 0.7724 & 1991.703 \\
\hline $\mathbf{3}$ & $\begin{array}{c}\text { Same floor to floor level } \\
\text { with Setback }\left(\mathrm{H}_{\mathrm{A}}=\mathrm{H}_{\mathrm{B}}\right)\end{array}$ & 36.80 & 42.00 & 0.0 & 0.636 & 0.372 & 1329.860 \\
\hline $\mathbf{4}$ & $\begin{array}{c}\text { Different floor to floor height } \\
\text { for different story }\left(\mathrm{H}_{\mathrm{A}} \neq \mathrm{H}_{\mathrm{B}}\right)\end{array}$ & 42.56 & 61.48 & 24.04 & 0.765 & 0.515 & 1820.480 \\
\hline $\mathbf{5}$ & $\begin{array}{c}\text { Different floor to floor height } \\
\text { with Same story }\left(\mathrm{H}_{\mathrm{A}} \neq \mathrm{H}_{\mathrm{B}}\right)\end{array}$ & 41.554 & 37.8 & 0.0 & 0.783 & 0.811 & 1782.708 \\
\hline $\mathbf{6}$ & $\begin{array}{c}\text { Different floor to floor height } \\
\text { with Setback }\left(\mathrm{H}_{\mathrm{A}} \neq \mathrm{H}_{\mathrm{B}}\right)\end{array}$ & 34.27 & 40.78 & 0.0 & 0.642 & 0.439 & 1108.210 \\
\hline
\end{tabular}



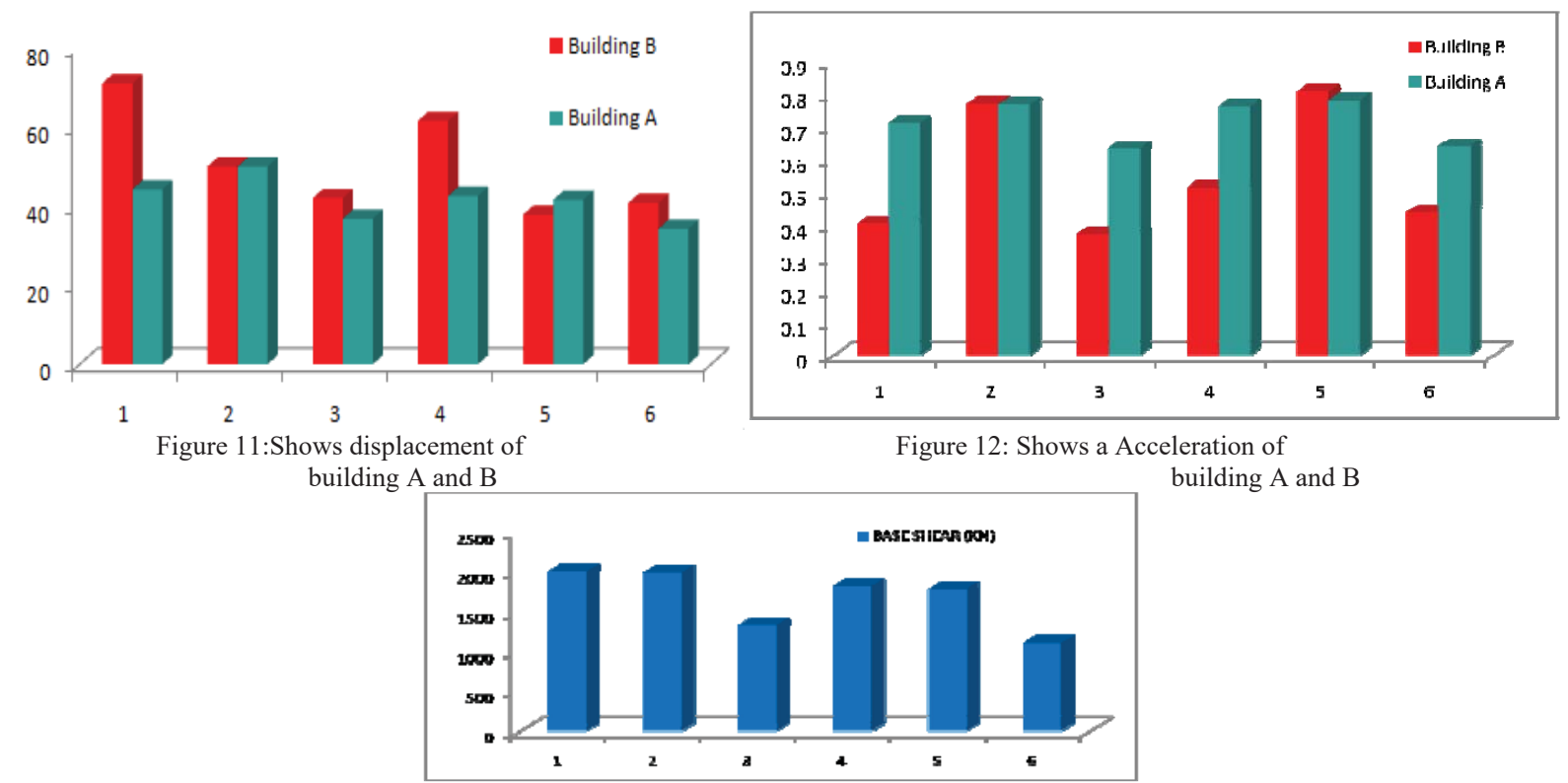

Figure 12: Shows a Acceleration of building A and B

Figure 13: Shows a Base shear for different pounding cases

\section{CONCLUSIONS}

The following conclusions were drawn by reviewing the result on impact of pounding in RC building.

- When comparing all six cases in the study, adjacent buildings with same floor level, different floor level and set back, out of phase movement is greater than expansion joint which creates impact force, which leads to permanent or repairable damage.

- Two adjacent R.C buildings, with different dynamic properties, vibrate out of phase which leading to pounding damage. The maximum response (displacement or deformation) is more in tall buildings than the shorter one as sown in linear and non-linear analysis.

- Adjacent buildings with a damper or link element which is less stiffer than the contact element are more effective avoiding pounding damage. Pounding must be checked in the buildings and then designed to avoid the pounding damages.

- Impact force increases considerably in the buildings with increased setback when compared with buildings at different floor levels. The adjacent R.C buildings consisting of same floor level should be designed with sufficient separation gap by considering dynamic analysis to prevent the effect of pounding due to earthquake in future.

\section{ACKNOWLEDGEMENTS}

I am thankful Professor and Head, Dept of Civil Engineering, Principal of ACS College of Engineering and, my beloved friends for their timely help rendered and the immense support extended for the submission of this paper.

\section{REFERENCES}

[1] Robert Jankowski., "Pounding Force Response Spectrum Under Earthquake Excitation", $\quad$ Engineering Structures, Vol.28, pp. 11491161, 2006.

[2] Susender Muthukumar and Reginald DesRoches., "A Hertz Contact Model With Nonlinear Damping for Pounding Earthquake Engineering and Structural Dynamics, Vol.35, pp. 811-828, 2006.

[3] H.L.Suresh, Ravindranatha, Shivananda S.M. and Tauseef M Honnyal, (2014), "A study of seismic pounding between adjacent buildings".

[4] Pradeep Kumar R, Kiran Kumar Reddy K and Chandra Sekhara Reddy T (2014), "Pounding problems in urban areas".

[5] Pradeep Kumar Ramancharla and ChennaRajaram (2012) "Three dimensional modeling of pounding".

[6] ChennaRajaram "A study of pounding between adjacent structures" Journal of Structural Engineering July 2014 pp. 1-11. 
[7] IS 1893-2002 (Part-1), "Criteria for Earthquake resistant design of structures, General provisions and buildings", Bureau of Indian Standards, New Delhi.

[8] IS 4326:1993, "Earthquake resistant design and construction of buildings Code Of Practice, Bureau of New Delhi.

[9] IS 456:2000, "Plain and Reinforced concrete - Code of practice", Bureau of Indian Standards, New Delhi. [10] Resistant Engineering Structures VII" by C.A. Brebbia,M. Phocas and P.Komodromos.

Indian Standards,

"Earthquake

[10] "Earthquake resistant design of structures VIII" Manish Shrikhande and Pankaj Agrawal. 